\title{
Changing the Financial Landscape of Africa: An Unusual Story of Evidence- informed Innovation, Intentional Policy Influence and Private Sector Engagement
}

\author{
Simon Batchelor
}

\begin{abstract}
This article uses the Steven Framework to show the influence of research on the policies and practices of mobile money transfer and mobile phone-enabled payments in Africa. While it is a muchdiscussed subject, few people know the wider narrative by which products such as M-Pesa were intentionally championed from outside the mobile phone industry. This championing was part of a much broader intentional strategy to change the landscape of financial service provision in Africa and to decrease the cost of international remittances. The origins of this strategy are to be found in research on the emerging behaviours associated with mobile phone use in Africa. There is an increasing call for evidence-based policymaking. The M-Pesa story shows a clear example of research informing (and thereby contributing to) policy development.
\end{abstract}

\section{Introduction}

As development researchers we spend much of our lives trying to demonstrate the policy influence of our work. There are times when the explicit connections between our research and its impact are tenuous at best. What follows is the story of a rare experience where, as a researcher, I had the honour of not just observing, but being a central political driver in a process of change.

The context is mobile money transfer and mobile phone-enabled payments. One of the most famous of the systems, with over 9 million subscribers within four years of its launch is M-Pesa in Kenya. The story of M-Pesa seems well documented, including papers on its origins (Hughes and Lonie 2007) and Wikipedia entries ${ }^{1}$ on its achievements. However, few people know the wider narrative by which M-Pesa was intentionally championed from outside the mobile phone industry. This championing was part of a much broader intentional strategy to change the landscape of financial service provision in Africa and to decrease the cost of international remittances. Further, it often gets lost or forgotten that the origins of this strategy are to be found in research - research on the emerging behaviours associated with mobile phone use in Africa. There is an increasing call for evidence-based policymaking, and here is a clear story of research informing (and thereby contributing to) policy development. The essence of this study, and its framing as an example of research to policy was first presented at the conference 'Beyond Scaling' in 2010.

\section{A framework on which to place the narrative}

There is a complex relationship between research, policy and practice. The pathways from conducting research, to adopting a policy, to changing practice and behaviour are neither linear nor straightforward. To address this complex relationship, Steven (2007: 9-15) suggested breaking down 'policy change' into a number of different types of influence. This definition moves beyond simply typecasting policy change as the 'passing of key legislation' or the issuing of a new government 'policy statement', and instead defines policy change as including:

1 Changing perceptions and public opinion;

2 Setting an agenda by reframing the way an issue is debated and creating pressure for change; 
3 Building networks that support delivery of change;

4 Developing capacity within organisations to allow them to understand and respond to an issue;

5 Changing institutions, for example influencing strategy and resource allocations within organisations (often government, but may be private sector).

The emphasis has shifted towards a better understanding about how policy is shaped by multiple relations and reservoirs of knowledge. The traditional question that focused on 'How can research be better transported from the research to the policy sphere?' has been largely replaced by a more complex set of questions around 'Why are some ideas in circulation amongst researchers and policymakers picked up and acted on, while others are ignored and disappear?'. And, while there are many factors that affect the translation of research findings into policy recommendations, greater focus is now paid to the values, motivation, and power of different actors shaping the policymaking process.

In the case study below the Steven model is used to frame the narrative, and to identify the key moments that led to a change in the policy environment. The story starts with research on the emerging behaviour of Africans with mobile phones.

\subsection{Research evidence inspires and informs}

In 2001 researchers, Gamos, alongside the Commonwealth Telecommunications

Organisation, began investigating the use of the mobile phone in Africa (McKemey et al. 2003).

Gamos is a small consultancy undertaking research on the social factors that affect development.

Our research suggested that although ownership of mobile phones was low, Africans had embedded telephones into their communication behaviours, and the potential for expansion of the use of mobile telephones was already visible.

Importantly, our research showed significant 'money transfer' insight. Forty-five per cent of respondents stated they 'use phone calls to discuss financial matters'. This alerted us to the importance of remittances to household finances, and the role of the telephone in easing the flow of remittances. 'Telecommunications operators should consider whether they can facilitate wire transfers and other remittances either directly or through teleshop proprietors' (McKemey et al. 2003).

Our research documented an innovative behaviour. In three different countries, people described how they were using airtime as a virtual currency. They would purchase a ticket in, say, the capital city, and text the code to their upcountry relatives. The relatives could choose to either put the code on their phone and gain airtime, or sell the airtime on to friends or merchants. This spontaneous use of airtime as a currency, with no outside or external civil society influence, suggested to us a huge pent-up demand for financial services, particularly the transfer of money within the country.

\subsection{Using the research to make a start (Steven [v])}

Steven talks of changing resource allocations. Having documented the use of airtime transfers between people, we approached a number of Telcos with their findings. The downside of the current spontaneous system (for the consumer) was that once the code had been used and put on a phone, it could no longer be moved. Consumers would therefore benefit from the ability to move airtime, or share airtime from one consumer to another. Mcel in 2004 in Mozambique quickly implemented airtime sharing. This was later emulated by other Telcos, and the more wellknown credit swapping product is with Safaricom in Kenya. This was a good start but it still meant that this 'virtual currency' had limitations. The more desired product would be a system that fully retained the cash in value of the registered electronic money.

We also considered whether international and domestic remittances could work together to strengthen livelihoods. We discovered that the global average flow of international remittances was $\$ 120$ billion but that the average transaction cost for this was said to be 12 per cent. We were shocked - this felt like an unnecessary and unfair tax on migrants.

\section{Building networks that support delivery of change (Steven [iii])}

Initially we set out to have informal conversations with people that we already knew.

InfoDev (World Bank) was a natural fit for the ideas. They embraced the core idea, and during 
the coming years, kept a view on mobile money as part of their brief. Steve Song, the Information and Communication Technologies for Development (ICT4D) Manager at the International Development Research Centre (IDRC, Canada), was helpful and gave an unexpected response. He suggested forming a research project to pilot money transfer and verbally committed funds for the work. David Woolnough, ICT4D Adviser at the Department for International Development (DFID, UK), was asked how this could be taken forward. He then helped support the sequence of work that built the networks required to take the ideas forward.

InfoDev pointed to the Consultative Group to Assist the Poorest (CGAP, World Bank) since microfinance was an obvious fit in the overall vision. During a Washington visit we approached CGAP and had conversations with a number of managers. CGAP took up the idea and have become a clear champion for mobile money and branchless banking. InfoDev also suggested contacting the Inter-American Development Bank (IADB). 'Gate crashing' a conference on the remittance corridor of America to Latin America in Washington, fellow champions were identified - Donald Terry, General Manager of the Multilateral Investment Fund (MIF) of the IADB (Terry and Wilson 2005) and Pedro De Vasconcelos (also of the IADB).

In March 2004, DFID made introductions to Vodafone. As documented in Hughes and Lonie (2007), Nick Hughes Corporate Affairs, Group Services had been considering how Vodafone might support rural banking. We presented the proposition that Vodafone could set up a mobile money transfer system in Africa. There was a key Vodafone-led workshop in April 2004, gathering bankers from across the Kenyan financial landscape. At this time Mr Les Baillie and Robert Gathu were leading the project of work for Safaricom in Kenya, supported by Nick Hughes. We managed to get an invitation to the workshop, and in private discussions with the participants the idea of a more direct mobile phone-enabled money transfer system was floated. After the workshop a plan was made for a pilot programme, a joint initiative between Faula, Safaricom and DFID. The DFID Challenge Fund agreement was modified and it is this plan for piloting a direct mobile phone money transfer system that is now archived.
It is important to acknowledge the role of Nick Hughes and Michael Joseph in taking these initial ideas forward. Michael Joseph, CEO of Safaricom, took the commercial lead and responsibility for pushing M-Pesa through. Nick Hughes moved to Kenya to support the development of the technology and the product. While we, the researchers, sowed the seeds of the idea, without the persistence and practical dayto-day management of these actors, the product might never have been launched.

We also approached other members of the telecom private sector, and one can trace contributions made over the years. Orange mobile now has three million clients for its West Africa proposition, and Zain Telecommunication Network has relaunched and competes with M-Pesa with its Zap money transfer proposition.

With a concern for an international remittance system, approaches were made to Western Union. At first we were rebutted with a now famous quote by a Western Union Manager (who will remain anonymous), that 'Mobile Phoneenabled money transfers will never threaten Western Union's core business model'. Later the networking proved attractive to Western Union.

During this time of engaging with the private sector, we came to the conclusion that one of the things that held back mobile phone-enabled money transfer was financial regulation.

\section{Setting an agenda by reframing the way an issue is debated and creating pressure for change (Steven [iv]) \\ 4.1 Political weight}

Several key opportunities for high-level lobbying and reframing presented themselves in an unusual way. In a three-minute conversation at an arts festival we put forward the 'elevator pitch' that he had refined to present to the Hon. Stephen Timms (MP) who was, in 2004,

Secretary to the Treasury in the UK.

International remittances stand at $\$ 120$ billion. The banks and money transfer outfits charge an average 12 per cent on this flow. Development aid stands at around $\$ 60$ billion. So the rich supporting the poor is 60 , while the poor supporting the poor is 120 - and being 'taxed' at 12 per cent. There are new opportunities presented by mobile phones that could reduce this transaction cost, and give people in Africa access to financial services. 
The resulting meeting was with the Hon. Timms' team, DFID, and the Financial Services Authority. Dominic Peachey, Technical Specialist and Senior Policy Adviser, Financial Services Authority (FSA, UK), became a champion for proportional risk legislation and travelled extensively sharing his views with his African (and global) colleagues in central banks.

Gamos was contracted by the Commission for Africa to write a background paper on the use of mobile phones in Africa based on their research. This led to attending a Commission meeting where the idea of mobile phone-enabled payment systems was tabled. The Commission report (Commission for Africa 2005) subsequently tabled the proposition that mobile phoneenabled payment systems could enhance the economic growth of Africa. The Commission report, and other lobbying through contacts at the US State Department, fed into the 31 st G8 Gleneagles Summit. The summit is most famous for setting the priorities of supporting Africa's economic development and combating global warming. However, unremarked on by the press, Paragraph 23 of the Africa Section of the Communiqué, point (b) stated

Support investment, enterprise development and innovation, ... to invest in SMEs and microfinance, and.... to increase access to financial services through increased partnerships between commercial banks and microfinance institutions, including through support for diversification of financial services available to the poor and effective use of remittances (emphasis added, G8 Gleneagles 2005).

While this may seem a small point, it more explicitly linked innovation and the private sector to financial inclusion and the possibilities of remittance flows. It lent a tremendous amount of political weight to the subsequent donor actions on mobile phone-enabled money transfer. In an official comparison of Africa Commission recommendations and the G8, the G8 archive website - G8 Information Centre - notes that the Communiqué para 23 (b) is directly related to the Africa Commission recommendations (Bayne 2005).

\subsection{Reframing regulation}

The above is about finding the political will for policy change. But there was also a 'practical' challenge for regulators and a need to reframe the way the issue was debated.

DFID had commissioned a key study by David Porteous, of Bankable Frontiers Associates (Porteous 2006). Working alongside CGAP and with the specific cooperation of the Central Bank of Kenya, the study outlined the challenges that might face regulators in understanding and developing policies that could accommodate 'transformational M-Banking'. This report was also seminal in that it defined the difference between additive and transformative banking with mobile phones - a change in the framing of the discourse (Steven [ii and iv]). This distinction became important because it set M-Pesa apart from the various offerings that some banks were proposing. The distinction was also a very key insight that assisted in reframing the regulatory debate.

\section{A new phase}

With the publication of the Gleneagles statement and the growing interest of the private sector and donors, DFID continued to plan a strategic input into the convergence of the digital world with the financial sector. Until now, the Gamos researchers had been using their own core funding to undertake lobbying actions. In August 2006, DFID recognised this championing of the sector, and issued a contract to Gamos through their framework agreement. Working with Bankable Frontiers Associates, the goal of the programme of work was 'To accelerate the start-up and rollout of transformational models of M-Banking, especially in low income countries'. Led by Justin Highstead, David Woolnough and Chris Bold at DFID, Gamos implemented a strategic plan to encourage cooperation across donors. A Knowledge Map commissioned by InfoDev and DFID (Porteous and Wishart 2006 ) provided insight as to where donors should invest strategically, and Gamos undertook a social network analysis to determine who the key players might be. We employed a then-emerging technique using graphical representation of social networks. The resulting map showed an important insight - it pointed to a key absence of a common space in the emerging convergence of digital and financial services!

The enabling contract was composed of four work packages. 


\section{Developing capacity within organisations to allow them to understand and respond to an issue (Steven [iv]) \\ 6.1 Adoption studies}

The story had started with research evidence on the changing behaviour of households in Africa.

There needed to be regular updating and support of the evidence base. In Senegal we were able to pilot within another programme a module of questions about remittance behaviours and their links to financial services and the use of mobile telephones. CGAP, Finscope, UNDP and the IDRC-funded RIA (Research ICT Africa)/LirneAsia/DIRSI Diálogo Regional Sobre la Sociedad de la Información ICT household surveys were all engaged in discussion. Research ICT Africa readily included key remittance modules into their regular household surveys in 16 African countries and soon generated a wealth of data. They continue to publish key studies on actual household behaviour in this converging arena.

\subsection{Rating enabling environments}

For such a change in the financial landscape to occur there needed to be a greater understanding of the regulatory environment. Building on DFID's work, the package sought to combine the GSMA's (Mobile Operator Association) plans for an initial 'Doing Business for M-Commerce Ranking', with a type of regulation diagnostics. CGAP identified this challenge as being about 'branchless banking' rather than restricting its enquiries to mobile phone models only. The outputs of this work package were a suite of knowledge products that informed regulators and decision-makers.

\section{Building networks and reframing the way an issue is debated (Steven [ii and iii]) \\ 7.1 Internet presence - a place to go?}

Initial explorations for research and regulatory diagnostic communications were for an independent website - however this was unlikely to generate the traction required to become a useful site without a huge investment of time and resources. CGAP started an M-Banking blog and InfoDev started an M-Payment knowledge portal as part of their site. Mobile Payments World were also part of these discussions as private sector engagement, ensuring any announcement of DFID or GGAP studies would be picked up and highlighted in their online magazine. Pages highlighting the work were explicitly posted on the DFID site.
In the longer term the CGAP blog remains the place to go for insights into transformational M-Payments, although GSMA have championed the idea through events (see below) and LinkedIn is used by Clarion events to discuss the issues.

\subsection{Hosting a conference}

The social network analysis identified the absence of a single conference space for this new converged arena. 'Face to face communication is the most effective means of influencing policy makers. A conference will, therefore, be a crucial element in ongoing efforts to make transformational M-Banking a reality' (DFID 2006). Working with GSMA, the first such conference occurred in Egypt in 2008. Although the donors DFID, CGAP and the International Finance Corporation (World Bank) all contributed, the conference was organised along commercial lines. It has since been an annual event, and has attracted the right mix of people, 'bringing together Telcos, banks, technology providers, donors and the regulators'.

Researchers also worked with Clarion events, AITECH, and Informa to build a set of commercial events to discuss mobile phone money transfer.

\section{Other observations from the Steven Framework}

The Steven model refers to significant changes in institutional resource allocation. With the advent of the Mobile Money Transfer conference, GSMA made a decision to bring conferences inhouse as a revenue stream. Perhaps more importantly, GSMA started a workstream for mobile money transfer. This resulted in an alliance with MasterCard, and eventually with Western Union. In discussions with Citibank and other private sector actors, the network came close to a creating a global clearing house for mobile-enabled transactions; however, this was stymied by the recession. CGAP has also been able to secure funds from the Bill \& Melinda Gates Foundation for a new technology innovation stream to its work.

The Steven model also talks about changing public perception. Gathering significant weighted public opinion to lobby for change was not part of the plan. We saw little reason to engage the public in consultation or participation in the lobbying process. However, with hindsight, 
another serendipitous connection enabled some key journalistic input and provided an important part of the build towards a global idea. We were connected to journalists at The Economist. An article in 2007 (The Economist 2007) created a significant stir among the stakeholders, and built on the suggestion that the world was about to change. The same contacts were connected to Developments, a well-presented and informed magazine made by DFID for the British public. This too created some 'buzz' among the wider development community (Batchelor 2005)

\section{Lessons learned}

What can we learn from examining this decade of championing?

\section{Base championing and influence on research}

It was the rise of transferring airtime as virtual currency that prompted the whole storyline. A key lesson in this rapidly changing world is to keep researching the behaviours of the poor. With the advent of ICT, behaviours, particularly information-seeking behaviours, and transactional economics, can rapidly change. Too often interventions start with an idea, and studies are conducted on how these interventions are leading to behaviour change. The key behaviour here was an innovation by the poor for the poor, and was not at the behest of any government or civil society activism.

\section{Include passion}

In the modern world it is not enough to report the bare facts. The world works on celebrity and 'confidence'. We felt passionate about the apparent injustice of a 12 per cent charge on international remittances, and the exclusion of the poor from financial systems. When lobbying, this passion came through. Discussions with the Commission for Africa turned from a light 30-minute briefing to a morning of dialogue.

\section{Create a communications strategy - reduce it to headlines}

We have perhaps all seen the passionate person who bores everyone with long-winded explanations of every detail. The researchers argued over how to present the data to politicians. The 'headliner' talked about ' 80 per cent using a telephone', ' 45 per cent discussing remittances'. My colleague, the more cautious detailed researcher, wanted to say ' 80 per cent of a non-nationally representative sample which has a slightly higher wealth balance than the nation as a whole... is using the telephone at least once in the last three months, including mobile phones and public phones'. However, such a statement does not run off the tongue easily. I would argue that headlines played an important role in the influencing strategy.

On the other hand, headlines need to be backed up by good research. When the headline is challenged, the detailed report needs to be on hand to justify the sentiment of the headline.

\section{Secure political will}

Writers on policy influencing all agree that decision-makers are influenced by politics. No matter how neutral a decision may seem there are likely to be some politics behind it. This is an article about contribution not attribution. We can note that when the Africa Commission put its weight behind the idea, there were increasing resources liberated from within DFID.

The role of the Treasury and the influence of Dominic Peachey from the FSA should not be underestimated. His mantra of proportional risk taking for regulation was coming from the mouth of one of the most powerful financial regulators in the world, with the backing of the UK Treasury. While African regulators make their own decisions, to have the UK making such statements was inevitably helpful to their case.

\section{Decide who should be engaged in the debate}

With hindsight the social network analysis was a very key piece of work. Out of 1,500 actors engaged with financial services (either with remittances, microfinance, E-Payments or banking), the analysis identified the key actors, the bridge-makers. Details of who could be a bridge between different communities, of who has high degrees of centrality to connect to the maximum number of people, of which key actors will be able to take the idea forward, are all directive when creating networks and negotiating the changing framework or policy space.

\section{Engage on a regular basis}

Having decided who to engage with, there was both a systematic attempt to attend events where those people may be, to engage with them on their own territory, and also to create new spaces where they might engage with each other. The Mobile Money Summit is now a regular 
forum for the players to gather and discuss the converging opportunity.

\section{Support with ongoing research evidence}

Debate needs to be supported with ongoing research. It is not enough to identify an emerging behaviour and then to assume that that behaviour will continue. Indeed, airtime-swapping in Kenya is now redundant as people can either directly swap credit or use the M-Pesa system to send money. It is important to have ongoing research that monitors emerging patterns - particularly in the realm of ICT which changes so quickly.

\section{Final comment}

For this case study, we have discussed the emergence of transformative M-Payments and

\section{Note}

1 Wikipedia, http://en.wikipedia.org/wiki/MPesa Accessed (accessed 3 August 2011).

\section{References}

Batchelor, S. (2005) 'Sending Money Outside the Envelope', Developments Magazine 31, London: Department for International Development, http://webarchive.nationalarchives.gov.uk/201 00823124637/ and www.developments.org.uk/ articles/loose-talk-saves-lives/ (accessed May 2012)

Bayne, N. (2005) Overcoming Evil with Good: Impressions of the Gleneagles Summit, 6-8 July 2005, www.g7.utoronto.ca/evaluations/ 2005gleneagles/bayne2005-0718.html (accessed May 2012)

Commission for Africa (2005) Our Common Interest: Report for the Commission for Africa, Glasgow: Commission for Africa, www.commissionforafrica.info/2005-report (accessed May 2012)

DFID (2006) Transformational M-Banking Terms of Reference, London: Department for International Development

The Economist (2007) 'A Cash Call', www.economist.com/node/8697424?story_id= 8697424 (accessed May 2012)

G8 Gleneagles (2005) The Gleneagles Communiqué, www.g8.utoronto.ca/summit/2005gleneagles/ index.html (accessed May 2012)
M-Banking - a case of intentional policy influence. I have related it to the Stevens model and shown how with hindsight ten years of research to policy that resulted in emerging private sector products and changed the financial landscape of Africa can be mapped onto the model.

Regarding that changing converged financial and ICT landscape, there is still much to do. It has been a privilege to be on this journey. The outcomes, which are the global reduction of remittance costs and the inclusion of millions into the financial landscape of Africa, have only reinforced my understanding that research can inform and drive action. It has convinced me that we need regular scans of emerging behaviour, and that good development works with the people.

Hughes, N. and Lonie, S. (2007) 'M-PESA: Mobile Money for the "Unbanked": Turning Cellphones into 24-Hour Tellers in Kenya', Innovations, www.mitpressjournals.org/doi/pdf/ 10.1162/itgg.2007.2.1-2.63 (accessed 13 June 2012)

McKemey, K. et al. (2003) Innovative Demand Models for Telecommunications Services, Reading: Gamos, www.telafrica.org/telafrica/pdfs/ FinalReport.pdf (accessed 13 June 2012)

Porteous, D. (2006) The Enabling Environment for Mobile Banking in Africa, London: Department for International Development

Porteous, D. and Wishart, N. (2006) Mobile Banking: Knowledge Map and Possible Donor Support Strategies, London: Department for International Development/Infodev

Steven, D. (2007) 'Evaluation and the New Public Diplomacy', presentation to the Future of Public Diplomacy, 842nd Wilton Park Conference, River Path Associates

Terry, D. and Wilson, R. (2005) Beyond Small Change: Making Migrant Remittances Count, Washington DC: Inter-American Development Bank 